\title{
Public Economies and the Endogenous Choice of Institutions*
}

\author{
Eduardo Zambrano ${ }^{\dagger}$
}

June, 2005

\begin{abstract}
In this paper I provide a framework in which to formalize the seminal work of Elinor Ostrom on the study of public economies, a prominent theoretical construct aimed to provide answers to the following questions: (a) Why some societies are able to solve their collective action problems and others are not? and (b) Why societies choose the particular institutions they choose from a vast array of possible choices?
\end{abstract}

${ }^{*}$ I would like to thank David Easley, Larry Blume, Kaushik Basu, David Kaplan, Garance Genicot, Francisco Rodríguez and participants at two Cornell seminar for their comments to a previous version of this work. All remaining shortcomings are mine.

${ }^{\dagger}$ Department of Finance, Mendoza College of Business, Notre Dame, IN 46556. E-mail: zambrano.1@nd.edu. Phone: 574-631-4597. Fax: 574-631-5255. 


\section{Introduction}

Why some societies are able to solve their collective action problems and others are not? Why societies choose the particular institutions they choose from a vast array of possible choices? In this article I provide a framework in which to formalize the seminal work of Elinor Ostrom on the study of public economies, a prominent theoretical construct aimed to provide answers to those important questions.

A public economy simply defined is a form of economic organization dedicated to the production, provision and consumption of collective goods. In several studies Ostrom and her co-authors have developed a set of hypotheses regarding the process by which public economies have evolved to provide and produce public goods and maintain common pool resources throughout the world. This process, according to Ostrom, cannot be summarized by simply arguing that "the market" is the resulting solution to all the situations in which one can internalize at the individual level the (external) effects of the collective action problem at hand and that "the state" is the resulting solution to all problems in which this is not the case. Instead, Ostrom argues, the real world exhibits a variety of institutions, all of them imperfect in nature, by which those collective action problems are routinely solved. These include "families and clans, neighborhood associations, communal organizations, trade associations, buyers and producer's cooperatives, local voluntary associations and 
clubs, special districts, international regimes, public service industries, arbitration and mediation associations, and charitable organizations," [12, p.36] among others.

Public economies are neither markets nor hierarchies and, according to Ostrom, they are not very well understood. It is Ostrom's opinion that there are two main open problems regarding the study of public economies. The first is that (a) we do not yet understand why some societies are able to solve their collective action problems and others are not. The second is that (b) we do not yet understand why societies choose the particular institutions they choose from the vast array of possible choices. In Ostrom's own words: "How a group of principals - a community of citizens- can organize themselves to solve the problems of institutional supply, commitment, and monitoring is still a theoretical puzzle." [9, p.29] These are the questions I set myself to answer in this paper in the context of a simple model of a public economy.

The organization of the rest of the paper is as follows: In Section 2 I present some elements of Ostrom's research on the study of public economies. In Section 3 I develop a simple model in which I can investigate the answers to questions (a) and (b) above. Section 4 concludes. 


\section{$2 \quad$ Public Economies}

In this section I draw from Ostrom [10] and Ostrom and Walker [12], where they present the main conceptual issues that surround the study of public economies.

Public economies are forms of economic organization "composed of collective consumption units of varying sizes that provide services by arranging for their production and regulating access to, patterns of use, and appropriation of collective goods." $[10$, pp. 6-7]

There are two key components to this definition. The first component acknowledges the need to organize consumption through the creation of collective consumption units. Whenever exclusion is problematic -as with public goods and commonpool resources- "creating a collective consumption unit larger than a household is essential to overcome problems of free riding and strategic preference revelation, to determine how costs will be shared among those who benefit, to arrange for production, and to regulate patterns of access, use, and appropriation." [10, p.7]

The second key component to the definition of a public economy is that the provision of services is viewed as a distinct process apart from production: "The primary reason for using a form of collective organization is to solve problems of provision. But once a collective consumption unit is established, how production is organized is an entirely separate question." [10, p. 7] Therefore, the producers 
in a public economy may or may not be the same organizing unit as the collective consumption unit that organizes the provision side.

\subsection{How to Study a Public Economy (I)}

The canonical manner in which modern economists and political scientists study public economies is by using tools from the theory of non-cooperative games. ${ }^{1}$ Those tools have been extremely influential in spreading the belief that phenomena like the "tragedy of the commons" are the resulting outcome from the process of provision and appropriation of collective goods in the presence of extremely sparse institutional structures.

While this exact belief is uncontested by the existing theoretical and empirical literatures on the topic, considerable disagreement exists regarding the extent to which individuals are passive recipients of such sparse institutional structures and the "tragedy" results unavoidable. According to Ostrom and Walker [12] these results are not the necessary outcome in a public economy precisely because individuals act to transform the rules of interaction into ones in which the "tragedy" can be avoided.

Kiser and Ostrom [5] distinguish two main levels of rules that cumulatively affect the actions taken and the outcomes obtained in any setting:

\footnotetext{
${ }^{1}$ For a prominent exception see Moulin [8].
} 
1. Operational rules directly affecting day-to-day decisions made by the participants in any setting, and

2. Constitutional and collective-choice rules affecting operational activities and outcomes through their effects in determining who is eligible and the specific rules to be used in changing operational rules.

Importantly, "once one recognizes that those involved in collective action may shift out of a current 'game' to a deeper-level game, the necessity of using multiple levels of analysis becomes apparent. All rules are nested in another set of rules that if enforced defines how the first set of rules can be changed." [12, p. 43] (my italics) Despite this, "most of the emphasis in the public choice tradition has been on predicting behavior within the structure of a game, rather than on the processes of organizing new games and on self-monitoring and sanctioning activities." $[12, \mathrm{p}$. 45] What is important for the analysis of public economies, however, is "to recognize that individuals can consciously decide to adopt their own rules that either replace or complement the rules governing an initial collective action situation." [12, p. 43]

\subsection{Providing Explanations of the Rules of the Game}

The key problem regarding the modern study of public economies is that we know little about how these rules that govern a collective action situation change over time. 
The point of view maintained by Ostrom and Walker [12] is that, while individual behavior reacts quickly once the rules that govern the situation are clear, the process of rule formation is rich in difficulties and uncertainties: "changes in deeper-level rules usually are more difficult and more costly to accomplish, thus increasing the stability of mutual expectations among individuals interacting according to a set of rules." [12, p. 43] This motivates Ostrom to assert that "given these levels of uncertainty about the basic structure of the problem appropriators face, the only reasonable assumption to make about the discovery and calculation processes employed [to find the best possible rules of the game] is that appropriators engage in a considerable amount of trial-and-error learning (...) By definition, trial-and-error methods involve errors, perhaps even disasters. Over time, appropriators gain a more accurate understanding of the physical world and what to expect from the behavior of others." $[9, \mathrm{p} .34]^{2}$

A very important aspect of Ostrom's view on the outcome of such process of rule formation is that there is no compelling reason to expect necessarily (first-best) "optimal" rules, yet one should expect the resulting institutions to improve over time whenever the individuals involved have had sufficient autonomy to craft their own institutions. I would like to conclude this very brief exposition of Ostrom's theoretical

\footnotetext{
${ }^{2}$ That rules of the game change over time in this fashion is of course not an idea that is arcane to social scientists. To wit: "the rules of the game (...) are all akin to equilibrium expectations; the product of long-term experience by a society of boundedly rational and retrospective individuals." Kreps [6, pp. 182-3]; "it would seem that an appropriate topic of a truly evolutionary game theory is evolution in the rules of the game." Blume [1, p. 31]
} 
insights with a quote that neatly summarizes the need for analytical complements to the received (non-cooperative) theory of collective action:

"[Both the experimental evidence and] the evidence from field settings show that individuals temporarily caught in a social-dilemma structure are likely to invest resources to innovate and change the structure itself in order to improve joint outcomes. They also strengthen the earlier evidence that the currently accepted, non-cooperative game theoretical explanation relying on a particular model of the individual does not adequately predict behavior in one-shot and finitely repeated social dilemmas. Cooperative game theory does not provide a better explanation. Since both cooperative and non-cooperative game theory predict extreme values, neither provides explanations for the conditions that tend to enhance or detract from cooperation levels." [11, p. 9]

\section{How to Study a Public Economy (II)}

In this section I study a public economy in a way that builds on the insights by Ostrom and her coauthors as spelled out in the previous section. The purpose of this section is to argue that a mixture of non-cooperative game theory and cooperative game theory provides an adequate language in which to study two of the main open 
questions in this literature: $(i)$ why some societies are able to solve their collective action problems and others are not, and (ii) why societies choose the particular institutions they choose from a vast array of possible choices.

Since I will attempt to show this in the context of a concrete economy I need to specialize the questions that I want the model to answer. Consider a situation in which there are two local public goods of different quality and there is heterogeneity of abilities of the potential users to profit from those public goods. Assume that the status quo situation is one of underprovision of the public goods, and that the set of possible reforms includes one that guarantees a (first-best) provision. The questions to ask are :(i) What determines whether this society is able to avoid the situation of critical underprovision? More concretely, is it more or less likely for the situation of underprovision to be avoided as the mean ability of the population increases? (ii) If the situation of underprovision cannot be avoided, what determines which particular institution is chosen? ( $i i i)$ Is it at least an 'improvement' over the status quo?

\subsection{The Setup}

I focus my attention to a situation in which there are two local public goods, 1 and 2, and a large quantity $I$ of individuals have to choose which of the two goods to 
consume. Individual $i^{\prime} s$ payoff from using good $j$ is given by

$$
U(i, j)=U_{j} \cdot \theta_{i}-p_{j}
$$

where $\theta_{i}$ denotes individual $i^{\prime} s$ ability to profit from consuming either public good (drawn from the uniform distribution on $[\underline{\theta}, \bar{\theta}]$, with $\underline{\theta}>0$ ), $U_{j}$ represents the quality of good $j$ and $p_{j}$ denotes the price (if any) that individuals have to pay to have access to good $j$. Individuals also have a choice to an outside option ("resource 0") valued at $U_{0} \cdot \theta_{i}$ by individual $i$. I make the following assumptions on the structure of preferences and on the distribution of abilities:

(A1) $U_{2}>U_{1}>U_{0}>0$

$$
\frac{2+\bar{\theta}-\underline{\theta}}{2(\bar{\theta}-\underline{\theta})}<\left(U_{2}+U_{1}-2 U_{0}\right)<1
$$

(A3) $\max \left\{\frac{1}{\bar{\theta}-\underline{\theta}}, \frac{1}{2 \underline{\theta}-\bar{\theta}}\right\}<\left(U_{2}-U_{1}\right)$

(A4) $\frac{3(\bar{\theta}-\underline{\theta})\left(U_{2}-U_{1}\right)+2}{(2 \bar{\theta}-\underline{\theta})\left(U_{2}-U_{1}\right)+1} \frac{\underline{\theta}\left(U_{2}-U_{1}\right)}{(\bar{\theta}-\underline{\theta})\left(U_{2}-U_{1}\right)+1}<\frac{\left(U_{2}-U_{1}\right)}{\left(U_{1}-U_{0}\right)}<\frac{3(\bar{\theta}-\underline{\theta})\left(U_{2}-U_{1}\right)+2}{(\bar{\theta}-2 \underline{\theta})\left(U_{2}-U_{1}\right)+1} \frac{\underline{\theta}\left(U_{2}-U_{1}\right)}{(\bar{\theta}-\underline{\theta})\left(U_{2}-U_{1}\right)+1}$

Assumption $A 1$ reveals the ordering on the quality of the goods. Assumption $A 2$ imposes bounds to the rewards from switching to a higher quality good. Assumption $A 3$ is a lower bound on the rewards from switching to good 2 from good 1. Assumption $A 4$ says that the rewards from switching to good 2 from good 1 are not 
too distant to rewards from switching to good 1 from the outside option. For this assumptions to hold simultaneously it is necessary that $(\bar{\theta}-\underline{\theta})>3$ as well, and I assume this too. Let $v_{j}(\theta)$ be the reservation price for good $j$ of an individual with ability $\theta$. It is a routine matter to show that

$$
\begin{aligned}
& v_{1}(\theta)=\theta\left(U_{1}-U_{0}\right) \text { and } \\
& v_{2}(\theta)=\theta\left(U_{2}-U_{0}\right) .
\end{aligned}
$$

Reservation prices are instrumental in determining the quantity of individuals that will choose either local public good or their outside option. Let $\mu_{j}=\mu_{j}\left(p_{1}, p_{2}\right)$ be the proportion of individuals that choose good $j$ at prices $p_{1}, p_{2}$ and $j=0,1,2$.

Associated with each local public good $j$ there is a producer $j$ who may or may not be able to charge a price for the good she produces, yet she bears the costs of producing the good. I assume that the cost of producing good $j$ when used by a proportion $\mu_{j}$ of $I$ individuals is given by $c_{j}\left(\mu_{j}\right)=\frac{I}{2} \mu_{j}^{2}$. A critical assumption that I will maintain throughout this analysis is that the only source of revenue that each producer has comes from the payments, if any, of the individuals that use her good. In particular, it is not an option for an producer to receive payments from people not using her good, or from the other producer. 


\subsection{The Status Quo Case: Non-excludability}

Legal or technological considerations may dictate that no individual can be excluded from the consumption of his good of choice. I model this situation as one in which the prices that the producers can effectively impose on the users of the goods are equal and such that profits vanish.

In this case for each individual $i$ of type $\theta$ in $[\underline{\theta}, \bar{\theta}]$ we have that $U(i, 2)=U_{2} \cdot \theta_{i}>$ $U(i, 1)=U_{1} \cdot \theta_{i}>U(i, 0)=U_{0} \cdot \theta_{i}$. As a consequence, all individuals choose good $2\left(\mu_{2}^{s}=1, \mu_{1}^{s}=\mu_{0}^{s}=0\right)$ and by definition producer 2 obtains profits equal to 0 (therefore, $\pi_{2}^{s}=\pi_{1}^{s}=0$ ). This situation with "too many" individuals using resource 2 and "too few" individuals using resource 1 is the one that I associate with the well-known "tragedy" results from the literature on public goods and common-pool resources. To make this suboptimality argument precise I now turn to an examination of the first-best allocation of this situation.

\subsection{The "first-best"}

As usual, an allocation $\mu^{f}$ of individuals to either local public good or to their outside options is a (first-best) efficient allocation whenever $\mu^{f}$ maximizes the sum of the payoffs of the individuals (including the producers) given their preferences and subject to the relevant technological constraints. This amounts to the choice of a 
function $\mu^{f}(i): I \rightarrow\{0,1,2\}$ that assigns every individual $i$ in $I$ to either good 1,2 , or to the outside option 0 . It is not hard to see that, because of the special structure of this problem, such function can be written as

$$
\mu^{f}(i)=\left\{\begin{array}{ccc}
2 & \text { if } & \theta_{i} \in\left[\theta_{2}^{f}, \bar{\theta}\right] \\
1 & \text { if } & \theta_{i} \in\left[\theta_{1}^{f}, \theta_{2}^{f}\right] \\
0 & \text { otherwise }
\end{array}\right.
$$

where $\theta_{1}^{f}$ and $\theta_{2}^{f}$ solve the problem below

$$
\max _{\theta_{1}, \theta_{2}} U_{o} \frac{\theta_{1}-\underline{\theta}}{\bar{\theta}-\underline{\theta}} I+U_{1} \frac{\theta_{2}-\theta_{1}}{\bar{\theta}-\underline{\theta}} I+U_{2} \frac{\bar{\theta}-\theta_{2}}{\bar{\theta}-\underline{\theta}} I-\frac{I}{2}\left(\frac{\theta_{2}-\theta_{1}}{\bar{\theta}-\underline{\theta}}\right)^{2}-\frac{I}{2}\left(\frac{\bar{\theta}-\theta_{2}}{\bar{\theta}-\underline{\theta}}\right)^{2} .
$$

Given function $\mu^{f}(i)$ one can compute the proportion $\mu_{j}^{f}$ of individuals that ought to be assigned to good $j$ according to the first-best principle. From the first-order (necessary and sufficient) conditions for the solution of this problem one obtains that

$$
\begin{aligned}
& \mu_{1}^{f}=U_{1}-U_{0} \\
& \mu_{2}^{f}=U_{2}-U_{0}, \text { and } \\
& \mu_{0}^{f}=1-\left(U_{2}+U_{1}-2 U_{0}\right),
\end{aligned}
$$

all numbers strictly between 0 and 1 because of assumptions $A 1$ and $A 2$. This 
proportions reveal that the status quo situation, that of non-excludability, is indeed one of underprovision of local public good 1.

It is convenient to define

$$
F B(\boldsymbol{\theta})=\sum_{i \in I} U_{\mu^{f}(i)} \cdot \theta_{i}-\frac{I}{2}\left(\mu_{1}^{f}\right)^{2}-\frac{I}{2}\left(\mu_{2}^{f}\right)^{2}
$$

as the maximized value of this first-best problem given the profile $\boldsymbol{\theta}$ of abilities and $F B_{-i}(\boldsymbol{\theta})$ as the maximized value of individuals other than $i$ from an efficient allocation when the profile of abilities is given by $\boldsymbol{\theta}$.

\subsection{Envisioning Reform}

The producers of the local public goods are not doing so well in the status quo regime: producers 1 and 2 are getting zero profits. Rather than playing the status quo game, the producers face the challenge of collectively choosing an alternative game in which they could fare better. To illustrate how this process of collective choice may be studied I endow the producers (and only the producers) with opportunities for choosing which game to play out of a small set that contains the status quo game. Before I continue with the explanation of how the process of game selection takes place let me introduce the set of games out of which the players will collectively choose. 


\subsection{The First Reform: Excludability Through Prices}

In the institutional setup corresponding to the first reform both producers are able to transform the legal and technological barriers that prevented them from effectively discriminating among types of users in the status quo game. The new rules are such that each producer chooses prices independently, however. As this is very important for the analysis let me stress it here: it is not feasible for them to choose prices jointly. As before, it is also not feasible for the producers to transfer profits among themselves.

An analysis of a situation formally similar to the one depicted here has been performed by Gabszewicz and Thisse [2] for the case of zero costs in the context of oligopolistic competition. Their method of analysis can be used to compute the proportion of individuals that will use either local public good and the outside option given positive prices. In what follows I will be interested in prices that support a pos-

itive proportion of individuals selecting both goods, and no proportion of individuals selecting the outside option. Let $\theta^{e}$ be such that

$$
v_{2}\left(\theta^{e}\right)-p_{2}=v_{1}\left(\theta^{e}\right)-p_{1}
$$


and consider the conjecture, subject to verification, that

$$
p_{2}>v_{1}(\underline{\theta})>p_{1}
$$

By construction, given prices $p_{1}$ and $p_{2}$ all individuals with abilities in the interval $\left[\underline{\theta}, \theta^{e}\right]$ will choose good 1 and all individuals with abilities in the interval $\left[\theta^{e}, \bar{\theta}\right]$ will choose good 2. Therefore, the proportions of individuals that will use each good in this scenario as a function of prices are given by

$$
\begin{aligned}
& \mu_{1}\left(p_{1}, p_{2}\right)=\frac{p_{2}-p_{1}}{\left(U_{2}-U_{1}\right)(\bar{\theta}-\underline{\theta})}-\frac{\underline{\theta}}{\bar{\theta}-\underline{\theta}} \\
& \mu_{2}\left(p_{1}, p_{2}\right)=1-\frac{p_{2}-p_{1}}{\left(U_{2}-U_{1}\right)(\bar{\theta}-\underline{\theta})}+\frac{\underline{\theta}}{\bar{\theta}-\underline{\theta}}, \text { and } \\
& \mu_{0}\left(p_{1}, p_{2}\right)=0 .
\end{aligned}
$$

The proof of this fact is virtually identical to the proof of Lemma 2 in Gabszewicz and Thisse [2] and I therefore omit it here.

With this information about the proportion of individuals that will select good 1 , the problem of each producer $j$ is to select the price $p_{j}^{e}$ that maximizes her profits, when taking the price $p_{-j}^{e}$ chosen by the other producer as given. Therefore, $p_{1}^{e}$ and 
$p_{2}^{e}$ are a solution to

$$
\begin{aligned}
& \max _{p_{1}} p_{1} \cdot \mu_{1}^{e}\left(p_{1}, p_{2}^{e}\right) I-\frac{I}{2} \mu_{1}^{e}\left(p_{1}, p_{2}^{e}\right)^{2} \text { and } \\
& \max _{p_{2}} p_{2} \cdot \mu_{2}^{e}\left(p_{1}^{e}, p_{2}\right) I-\frac{I}{2} \mu_{1}^{e}\left(p_{1}^{e}, p_{2}\right)^{2} .
\end{aligned}
$$

From the strict concavity of the objective functions of the producers it follows that their best-response functions are unique and given by

$$
\begin{aligned}
& p_{1}=\frac{1-a}{b} \frac{1+b}{2+b}+\frac{1+b}{2+b} p_{2} \text { and } \\
& p_{2}=\frac{a}{b} \frac{1+b}{2+b}+\frac{1+b}{2+b} p_{1},
\end{aligned}
$$

where $b=\frac{1}{(\bar{\theta}-\underline{\theta})\left(U_{2}-U_{1}\right)}<1$ and $1<a=\frac{\bar{\theta}}{\bar{\theta}-\underline{\theta}}<(2+b)$ (by assumptions $A 1-A 2$ ). This pair of equations for the prices have a unique solution $p_{1}^{e}$ and $p_{2}^{e}$ given by

$$
\begin{aligned}
& p_{1}^{e}=\frac{1+b}{b} \frac{2+b-a}{3+2 b} \text { and } \\
& p_{2}^{e}=\frac{1+b}{b} \frac{a+1+b}{3+2 b} .
\end{aligned}
$$

Notice that both prices are strictly positive and that $p_{2}^{e}>v_{1}(\underline{\theta})>p_{1}^{e}$, as conjectured. A proof of this can be found in the Appendix.

With this in hand one can compute the proportion of individuals that will select 
each good in equilibrium

$$
\begin{aligned}
& \mu_{1}^{e}=\frac{2+b-a}{3+2 b}, \\
& \mu_{2}^{e}=\frac{a+1+b}{3+2 b}, \text { and } \\
& \mu_{0}^{e}=0 .
\end{aligned}
$$

and the profits that both producers collect:

$$
\begin{aligned}
& \pi_{1}^{e}=\frac{2+b}{2 b}\left(\frac{2+b-a}{3+2 b}\right)^{2} I, \text { and } \\
& \pi_{2}^{e}=\frac{2+b}{2 b}\left(\frac{a+1+b}{3+2 b}\right)^{2} I .
\end{aligned}
$$

This is, therefore, what the producers can expect to obtain if this is the game that they choose to play.

\subsection{The Second Reform: Implementing the First-Best Out- come}

The second reform that I will allow in the set of possible reforms is an institutional setup that requires the producers to implement the efficient (first-best) outcome described earlier. This implementation is naturally not a trivial matter because the 
producers of the goods neither have the information about the abilities of the individuals in the economy nor can they force the individuals to participate in the institution they design to elicit an efficient consumption of the goods. As a consequence, inducing them through appropriate compensation to reveal the information necessary for the implementation of the efficient outcome can be so costly to the producers that it may make it undesirable, from their point of view, to implement it at all. The point, therefore, of allowing the producers the option to bond themselves to an efficient production of the public goods is to see whether they would, jointly and voluntarily, take this option in a situation of cooperative bargaining.

The setup is, to be sure, one in which each producer is required to select a method for inducing a (first-best) efficient consumption of the public good under her administration. The method may or may not involve communication of any kind between any of the participants in the economy and may or may not involve compensation contingent on the content of such communication. In this scenario for reform, each producer has the ability to arbitrarily exclude any individual from employing the public good under her administration, yet each producer is not allowed to accept compensation neither from the other producer nor from individuals using the good that is not under her administration.

It turns out that there is an easy way to characterize what would happen in such 
a situation. It is a dominant strategy for each producer to use the Vickrey-ClarkeGroves (VCG) mechanism (among the class of efficient mechanisms). This is because of a result by Krishna and Perry [7] according to which this mechanism maximizes the payments collected from each individual participating in the mechanism among the class of (first-best) efficient mechanisms.

I will go over the construction of this mechanism briefly following the approach in Krishna and Perry [7]. The VCG mechanism with basis $\underline{\theta}$, denoted by $\left(\mu^{f}, p^{v}\right)$, is defined as one in which each individual $i$ is invited to give a report $r_{i}$ of his abilities, is assigned to a public good and charged a price for the employment of this public good that is contingent on the report. The payments required from each individual willing to participate in the mechanism are given by

$$
p^{v}(\mathbf{r}, i)=\left[F B\left(\underline{\theta}, \mathbf{r}_{-i}\right)-F B_{-i}(\mathbf{r})\right]-U_{0} \cdot \underline{\theta},
$$

where $F B\left(\underline{\theta}, \mathbf{r}_{-i}\right)$ is the (maximized) value of the first-best problem given the profile $\left(\underline{\theta}, \mathbf{r}_{-i}\right)$ of abilities and $F B_{-i}(\mathbf{r})$ as the (maximized) value of individuals other than $i$ from an efficient allocation when the profile of abilities is given by $\mathbf{r}$. Notice that the first best rule $\mu^{f}$ assigns an individual with ability $\underline{\theta}$ to his outside option. Therefore, an individual $i$ with ability $\underline{\theta}$ is the "most reluctant" type of agent $i$ in the sense that his gain from participating in the $V G G$ mechanism is the least among all the types 
of $i$. As a consequence, the payment rule for individual $i$ can be written as

$$
p^{v}(\mathbf{r}, i)=\left[U_{0} \cdot \underline{\theta}+F B_{-i}\left(\underline{\theta}, \mathbf{r}_{-i}\right)-F B_{-i}(\mathbf{r})\right]-U_{0} \cdot \underline{\theta}=F B_{-i}\left(\underline{\theta}, \mathbf{r}_{-i}\right)-F B_{-i}(\mathbf{r}),
$$

The amount $p^{v}(\mathbf{r}, i)$ represents the externality that $i$ exerts on the rest of the economy by being of ability $r_{i}$ rather than $\underline{\theta}$. It is the difference between the welfare of others "without him" and the welfare of others "with him." For the problem at hand the payment rule is

$$
p^{v}(\mathbf{r}, i)=\left\{\begin{array}{lrl}
p_{2}^{v}=\theta_{1}^{f}\left(U_{1}-U_{0}\right)+\theta_{2}^{f}\left(U_{2}-U_{1}\right) & \text { if } & r_{i} \in\left[\theta_{2}^{f}, \bar{\theta}\right] \\
p_{1}^{v}=\theta_{1}^{f}\left(U_{1}-U_{0}\right) & \text { if } & r_{i} \in\left[\theta_{1}^{f}, \theta_{2}^{f}\right] \\
p_{0}^{v}=0 & \text { otherwise. }
\end{array}\right.
$$

It is not hard to see that truth-telling is a weakly dominant strategy in this mechanism and thus it is also incentive compatible. The proof of this is in the Appendix. The profits that each producer gets from using a pricing scheme as in this mechanism are given by

$$
\begin{aligned}
\pi_{1}^{v} & =p_{1}^{v} \mu_{1}^{f} I-\frac{I}{2}\left(\mu_{1}^{f}\right)^{2}, \text { and } \\
\pi_{2}^{v} & =p_{2}^{v} \mu_{2}^{f} I-\frac{I}{2}\left(\mu_{2}^{f}\right)^{2},
\end{aligned}
$$


or

$$
\begin{aligned}
& \pi_{1}^{v}=\left(\theta_{1}^{f}-\frac{1}{2}\right)\left(U_{1}-U_{0}\right)^{2} I, \text { and } \\
& \pi_{2}^{v}=\left[\left(\theta_{1}^{f}-\frac{1}{2}\right)+(\bar{\theta}-\underline{\theta})\left(U_{2}-U_{1}\right)\right]\left(U_{2}-U_{0}\right)^{2} I .
\end{aligned}
$$

\subsection{The Grand Game: A mixture of cooperative and non- cooperative behavior}

The existence of a status quo situation ("non-excludability") coupled with the reforms described above ("excludability" and "first-best reform") I study as a situation in which in the first stage the players cooperatively choose, according to Nash's rules of axiomatic bargaining, ${ }^{3}$ which game to play, while in the second stage they play a Nash equilibrium of the chosen game. I call this the Nash-Nash solution of the public economy problem. Formally, $G^{s}$ is the status quo game described above, and $G^{e}$ and $G^{v}$ stand for the excludability case and the first-best reform, respectively. The Nash-Nash solution of the public economy problem under study then requires the application of the Nash bargaining solution over the Nash equilibrium payoffs of the games $G^{s}, G^{e}$ and $G^{v}$, with the disagreement payoffs given by the equilibrium

\footnotetext{
${ }^{3} \mathrm{~A}$ justification for the application of Nash's bargaining solution in this setting can be found in Kaneko [4].
} 
payoffs of the status quo game $G^{s}$.

\subsubsection{Analysis}

As there is not a straightforward manner of comparing the products $\pi_{1}^{v}\left(\pi_{2}^{v}-\pi_{2}^{s}\right)$ and $\pi_{1}^{e}\left(\pi_{2}^{e}-\pi_{2}^{s}\right)$ for computing this solution in general I consider evaluating those products along the curves $\left(\pi_{1}^{v}(m), \pi_{2}^{v}(m)\right)$ and $\left(\pi_{1}^{e}(m), \pi_{2}^{e}(m)\right)$ as the mean $m$ of distribution of abilities (keeping the variance constant) varies in the interval $[\underline{m}, \bar{m}]$, where $\underline{m}$ and $\bar{m}$ must satisfy $\left(\frac{3}{2}+b\right)(\bar{\theta}-\underline{\theta}) \geq \bar{m}>\underline{m} \geq \frac{3}{2}$ because of $A 1-A 4$. It turns out that for $m$ close enough to $\underline{m} \pi_{1}^{v}(m)$ is negative, so that producer 1 will always reject any proposal to select game $G^{v}$ because she does better in the status quo game $G^{s}$, where she obtains zero profits. Interestingly, the product $\pi_{1}^{v}\left(\pi_{2}^{v}-\pi_{2}^{s}\right)$ is strictly increasing in $m$ and the product $\pi_{1}^{e}\left(\pi_{2}^{e}-\pi_{2}^{s}\right)$ is strictly decreasing in $m$. Indeed, as $m$ approaches $\bar{m}$, profits $\pi_{1}^{e}(m)$ approach zero and therefore the product $\pi_{1}^{e}\left(\pi_{2}^{e}-\pi_{2}^{s}\right)$ approaches zero as well. Therefore, there is a mean income $m^{*}$ such that if $m>m^{*}$ the Nash-Nash solution of the public economy problem picks game $G^{v}$ and if $m<m^{*}$ the Nash-Nash solution picks game $G^{e}$. The details are worked out in Appendix 2. 


\subsection{Discussion}

With this in hand I am ready to answer the questions posed at the beginning of this section: (i) the situation of critical underprovision can arise if the revenue raised by producer 1 in game $G^{v}$ is too small so that it would force producer 1 to run a deficit in order to induce an efficient consumption of good 1. This will happen if the mean ability of the potential users of the goods is sufficiently low. Therefore, the situation of underprovision of the best good is more likely to be avoided as the mean ability of the population increases.

(ii) This is not to say that the first-best efficient outcome will be selected as soon as producer 1 ceases to run a deficit. This is because the profits that she obtains in the excludability case may still be much higher than those she obtains in the efficient allocation game. Interestingly, as the mean ability increases there are two effects that weaken the appeal of the excludability case in favor of the first-best game.

First, that the profits of both producers are increasing in mean abilities in the first-best situation. This is so because the first-best allocation, and therefore costs, do not depend on the mean ability, but willingness to pay for the consumption of the goods increases uniformly across individuals with the mean ability. This simply means more revenues for the producers with no added costs. Second, that the profits of producer 2 are increasing in mean ability but the profits of producer 1 actually 
decrease with mean ability in the excludability case. This is so because, with an increase in mean ability, every individual's valuation of both public goods increases, but the valuation of the best good increases relatively more than that of the worst good. This increase in relative valuation leads to an increase in both the price charged by producer 2 and the proportion of individuals using good 2 . The combination of this two effects jointly explain how changes in $m$ affect which non-cooperative game will be selected cooperatively as the Nash-Nash solution of the public economy problem.

(iii) The excludability case does not yield a first-best allocation of individuals to all goods, but it yields a smaller underprovision of the best good. This is no proof of the normative superiority of this outcome relative to the status quo situation, however, because everybody in this economy, except for the producers, is worse off at either reform when we compare their payoffs to those which obtain in the status quo situation. This is a crude reminder of the fact that, when the opportunities for redistribution are severely restricted, there is no reason to believe that an increase in efficiency has anything to say about the overall welfare of society. 


\section{Conclusions}

When applied to concrete economic problems the model developed to formalize Ostrom's theories of public economies helps support conclusions such as the following: (i) A "first best" reform need not be selected as the Nash-Nash solution of a public economy problem even if it arises as an equilibrium of one of the possible games to be played, and (ii) A "first best" reform may be chosen as the Nash-Nash solution of a public economy problem yet the choice may force some players (with no bargaining power) to payoffs that are dominated by those they could have obtained in the status quo game. These results are in line with an old and sometimes forgotten principle from the public economics literature: that when opportunities for redistributing payoffs among the players are severely restricted, a "first best" reform may neither be predictively accurate nor normatively desirable. That this principle is overlooked so frequently in the analysis of public policies has recently motivated the work of many authors, including Hammond [3], Ray and Vohra [13] and Moulin [8].

\section{References}

[1] Blume, L. "Population Games," in Arthur, W., D. Lane and S. Durlauf (eds.) The Economy as an Evolving Complex System II, Reading, MA: Addison- 
Wesley, 1997.

[2] Gabszewicz, J. and J.-F. Thisse, "Price Competition, Quality and Income Disparities," Journal of Economic Theory 20, 340-359, 1979.

[3] Hammond, P., "Theoretical Progress in Public Economics: A Provocative Assessment," Oxford Economic Papers 42, 6-33, 1990.

[4] Kaneko, Mamoru, "An Extension of Nash Bargaining Problem and the Nash Social Welfare Function," Theory and Decision 12, 135-148, 1980.

[5] Kiser, L. and E. Ostrom, "The Three Worlds of Action: A Metatheoretical Synthesis of Institutional Approaches," in E. Ostrom (ed.) Strategies of Political Inquiry, 179-222, Beverly Hills, CA: Sage, 1982.

[6] Kreps, D., Game Theory and Economic Modelling, Oxford, UK: Oxford University Press, 1990.

[7] Krishna, V., and M. Perry, "Efficient Mechanism Design," manuscript, 2000.

[8] Moulin, H., Cooperative Microeconomics, Princeton: Princeton University Press, 1995.

[9] Ostrom, E., Governing the Commons. The Evolution of Institutions for Collective Action, Cambridge, UK: Cambridge University Press, 1990. 
[10] _____, The Comparative Study of Public Economies, Memphis, TN: P.K.

Seidman Foundation, 1998.

[11] ______, "A Behavioral Approach to the Rational Choice Theory of Collective Action," American Political Science Review 92, 1-22, 1998.

$[12]$ , and J. Walker, "Neither Markets nor States: Linking Transformation

Processes in Collective Action Arenas," in D. Mueller, (ed.) Perspectives on Public Choice: A Handbook, Cambridge, UK: Cambridge University Press, 1997.

[13] Ray, D., and R. Vohra, "Equilibrium Binding Agreements," Journal of Economic Theory 73, 30-78, 1997.

\section{Appendix}

\subsection{Proof that $0<p_{1}^{e}<v_{1}(\underline{\theta})<p_{2}^{e}$ in the first reform}

The price $p_{j}^{e}$ that producer $j$ charges to users of good $j$ in a non-cooperative price competition scenario is given, in equilibrium, by

$$
\begin{aligned}
& p_{1}^{e}=\frac{1+b}{b} \frac{2+b-a}{3+2 b} \text { and } \\
& p_{2}^{e}=\frac{1+b}{b} \frac{a+1+b}{3+2 b} .
\end{aligned}
$$


Clearly, $p_{2}^{e}>0$. Price $p_{1}^{e}$ is also positive because $A 1-A 3$ guarantee that $a<2+b$.

I now check that $p_{1}^{e}<v_{1}(\underline{\theta})<p_{2}^{e}$. From assumption $A 4$ we have that

$$
\frac{3+2 b}{a+1+b} \frac{a-1}{1+b}<\frac{\left(U_{2}-U_{1}\right)}{\left(U_{1}-U_{0}\right)}<\frac{3+2 b}{2+b-a} \frac{a-1}{1+b}
$$

Rearranging this expression one obtains

$$
\frac{3+2 b}{a+1+b} \frac{b}{1+b}<\frac{1}{\left(U_{1}-U_{0}\right) \underline{\theta}}<\frac{3+2 b}{2+b-a} \frac{b}{1+b}
$$

which can be written as

$$
\frac{(1+b)}{b}\left(\frac{2+b-a}{3+2 b}\right)=p_{1}^{e}<\underline{\theta}\left(U_{1}-U_{0}\right)=v_{1}(\underline{\theta})<\frac{(1+b)}{b}\left(\frac{a+1+b}{3+2 b}\right)=p_{2}^{e},
$$

and that is what we wanted to show. 


\subsection{Proof that participating and truth-telling is a weakly dominant strategy for the individuals in the second re-} form

For the problem at hand the payment rule is

$$
p_{i}^{v}(\mathbf{r})= \begin{cases}\theta_{1}^{f}\left(U_{1}-U_{0}\right)+\theta_{2}^{f}\left(U_{2}-U_{1}\right) & \text { if } \quad r_{i} \in\left[\theta_{2}^{f}, \bar{\theta}\right] \\ \theta_{1}^{f}\left(U_{1}-U_{0}\right) & \text { if } r_{i} \in\left[\theta_{1}^{f}, \theta_{2}^{f}\right] \\ 0 & \text { otherwise }\end{cases}
$$

Consider an individual $i$ with ability $\theta_{i} \in\left[\underline{\theta}, \theta_{1}^{f}\right]$. If the individual reports his true ability he gets to pay nothing, is assigned to good 0 and ends up with a payoff equal to $U_{0} \cdot \theta_{i}>0$. If the individual reports any other ability in the interval $\left[\underline{\theta}, \theta_{1}^{f}\right]$ he gets exactly the same payoff as before, so he has no incentives to deviate to any such report. If the individual reports an ability in the interval $\left(\theta_{1}^{f}, \theta_{2}^{f}\right]$ he is assigned to good 1 , pays a price equal to $\theta_{1}^{f}\left(U_{1}-U_{0}\right)$ and gets a payoff equal to $U_{1} \cdot \theta_{i}-\theta_{1}^{f}\left(U_{1}-U_{0}\right)=U_{1}\left(\theta_{i}-\theta_{1}^{f}\right)+\theta_{1}^{f}\left(U_{0}\right)$. This payoff is smaller than that obtained by reporting her true type, however, since $U_{1}\left(\theta_{i}-\theta_{1}^{f}\right)+\theta_{1}^{f} \cdot U_{0}-U_{0} \cdot \theta_{i}=$ $\left(U_{1}-U_{0}\right)\left(\theta_{i}-\theta_{1}^{f}\right)<0$. If the individual reports an ability in the interval $\left(\theta_{2}^{f}, \bar{\theta}\right]$ he is assigned to good 2 , pays a price equal to $\theta_{1}^{f}\left(U_{1}-U_{0}\right)+\theta_{2}^{f}\left(U_{2}-U_{1}\right)$ and gets 
a payoff equal to $U_{2} \cdot \theta_{i}-\theta_{1}^{f}\left(U_{1}-U_{0}\right)-\theta_{2}^{f}\left(U_{2}-U_{1}\right)$. The difference between this payoff and the payoff that obtains from reporting an ability in the interval $\left(\theta_{1}^{f}, \theta_{2}^{f}\right]$ is given by

$$
U_{1} \cdot \theta_{i}-\theta_{1}^{f}\left(U_{1}-U_{0}\right)-\theta_{2}^{f}\left(U_{2}-U_{1}\right)-U_{1}\left(\theta_{i}-\theta_{1}^{f}\right)-\theta_{1}^{f}\left(U_{0}\right)
$$

which can be written as $\left(U_{2}-U_{1}\right)\left(\theta_{i}-\theta_{2}^{f}\right)<0$. Therefore, reporting an ability in the interval $\left(\theta_{2}^{f}, \bar{\theta}\right]$ is a dominated strategy. From all this, it follows that truth-telling is a weakly dominant strategy. Also, since the individual gets as payoff of at least the value of her outside option, then the participation constraint is also met.

The arguments for individuals with abilities in the intervals $\left(\theta_{1}^{f}, \theta_{2}^{f}\right]$ and $\left(\theta_{2}^{f}, \bar{\theta}\right]$ to show that truth-telling is a dominant strategy are analogous to the one just given and I omit them here.

\subsection{Details on the effect of changes in mean ability $m$ on the Nash-Nash solution of the public economy problem}

Since the mean ability $m$ is defined as $\left(\frac{\bar{\theta}+\underline{\theta}}{2}\right)$ the terms $\bar{\theta}$ and $\underline{\theta}$ can be defined as $\bar{\theta}=m+\frac{1}{2}(\bar{\theta}-\underline{\theta}), a=\frac{m}{(\bar{\theta}-\underline{\theta})}+\frac{1}{2}$ and $\theta_{1}^{f}=m+(\bar{\theta}-\underline{\theta})\left[\frac{1}{2}-\left(U_{1}+U_{2}-2 U_{0}\right)\right]$ for fixed $(\bar{\theta}-\underline{\theta})$. In what follows all functions of $m$ are assumed to have domain equal 
to $[\underline{m}, \bar{m}]$. We can therefore compute the expressions

$$
\begin{aligned}
& \frac{\partial \pi_{1}^{e}}{\partial m}=-\frac{2+b}{b}\left(\frac{2+b-a}{3+2 b}\right) I\left(\frac{1}{(\bar{\theta}-\underline{\theta})(3+2 b)}\right)<0, \\
& \frac{\partial \pi_{2}^{e}}{\partial m}=\frac{2+b}{b}\left(\frac{a+1+b}{3+2 b}\right) I\left(\frac{1}{(\bar{\theta}-\underline{\theta})(3+2 b)}\right)>0
\end{aligned}
$$

and

$$
\begin{aligned}
& \frac{\partial \pi_{1}^{v}}{\partial m}=\left(U_{1}-U_{0}\right)^{2} I>0 \\
& \frac{\partial \pi_{2}^{v}}{\partial m}=\left(U_{2}-U_{0}\right)^{2} I>0 .
\end{aligned}
$$

Notice that the product $\pi_{1}^{e} \pi_{2}^{e}$ is continuous and strictly decreasing in $m$

$$
\begin{aligned}
& \frac{\partial \pi_{1}^{e} \pi_{2}^{e}}{\partial m}= \frac{\partial \pi_{1}^{e}}{\partial m} \pi_{2}^{e}+\frac{\partial \pi_{2}^{e}}{\partial m} \pi_{1}^{e} \\
&=-\left\{\frac{2+b}{b}\left(\frac{2+b-a}{3+2 b}\right) I\left(\frac{1}{(\bar{\theta}-\underline{\theta})(3+2 b)}\right)\left[\frac{2+b}{2 b}\left(\frac{a+1+b}{3+2 b}\right)^{2} I\right]\right\} \\
&+\left\{\frac{2+b}{b}\left(\frac{a+1+b}{3+2 b}\right) I\left(\frac{1}{(\bar{\theta}-\underline{\theta})(3+2 b)}\right) \frac{2+b}{2 b}\left(\frac{2+b-a}{3+2 b}\right)^{2} I\right\} \\
&= {\left[\frac{(2+b)^{2}}{2 b^{2}} \frac{(a+1+b)(2+b-a)}{(3+2 b)^{4}} \frac{I^{2}}{(\bar{\theta}-\underline{\theta})}\right][1-2 a]+\frac{\partial \pi_{1}^{e}}{\partial m}<0 } \\
& {[-] }
\end{aligned}
$$


and that the product $\pi_{1}^{v}\left(\pi_{2}^{v}-\pi_{2}^{s}\right)$ is continuous and strictly increasing in $m$

$$
\frac{\partial \pi_{1}^{v} \pi_{2}^{v}}{\partial m}=\frac{\partial \pi_{1}^{v}}{\partial m} \pi_{2}^{v}+\frac{\partial \pi_{2}^{v}}{\partial+]} \pi_{1}^{v}>0
$$

Now evaluate the function $d(m)=\pi_{1}^{e} \pi_{2}^{e}-\pi_{1}^{v} \pi_{2}^{v}$. It is continuous and strictly decreasing. Moreover, this function is such that, for $m$ close enough to $\underline{m}, d(m)>0$ and for $m$ close enough to $\bar{m}, d(m)<0$. Then, by the intermediate value theorem, there is a unique $m^{*}$ such that if $m<m^{*}$ then $\pi_{1}^{e} \pi_{2}^{e}>\pi_{1}^{v} \pi_{2}^{v}$ and if $m>m^{*}$ then $\pi_{1}^{e} \pi_{2}^{e}<\pi_{1}^{v} \pi_{2}^{v}$, that is, the Nash-Nash solution of the public economy problem selects game $G^{e}$ if $m<m^{*}$ and game $G^{v}$ if $m>m^{*}$. 